Article

\title{
Numerical Study on Solidification Behavior and Structure of Continuously Cast U71Mn Steel
}

\author{
Qing Fang, Hongwei Ni *, Hua Zhang, Bao Wang and Chengsong Liu \\ The State Key Laboratory of Refractories and Metallurgy, Wuhan University of Science and Technology, \\ Wuhan 430081, China; qfang525@163.com (Q.F.); huazhang@wust.edu.cn (H.Z.); \\ wangbao1983@wust.edu.cn (B.W.); liuchengsong@wust.edu.cn (C.L.) \\ * Correspondence: nihongwei@wust.edu.cn; Tel.: +86-027-6886-2811
}

Received: 26 September 2017; Accepted: 31 October 2017; Published: 7 November 2017

\begin{abstract}
The solidification behavior and structure of continuous casting high rail U71Mn bloom, under different secondary cooling conditions and superheat, were numerically investigated using the Cellular Automaton-Finite Element (CAFE) model implemented with ProCAST software. Nail shooting and macro etch experiments of the bloom samples under different cooling conditions were conducted to verify the model of macroscopic solidification and structure. The results showed that the simulated results of the solidified shell and solidification structure are basically consistent with experimental results. The secondary cooling condition has little effect on the grain size and distribution of the bloom, while both the bloom surface and corner temperatures are higher and the temperature rise at the beginning of the air-cooling zone is smaller under the super-slow cooling condition. The percentage of center-equiaxed grains decreases from $44.6 \%$ to $20.1 \%$ and the grain average radius increases from 1.025 to $1.128 \mathrm{~mm}$ when the superheat increases from 15 to $40 \mathrm{~K}$, with little change in the grain size occurring between 15 and $20 \mathrm{~K}$. Moreover, for a step increase in the superheat of $5 \mathrm{~K}$, the solidification end is lengthened by about $0.19 \mathrm{~m}$ and the surface temperature is enhanced by $3 \mathrm{~K}$. The super-slow secondary cooling condition with the superheat controlled within $20 \mathrm{~K}$ is suitable for big-bloom casting.
\end{abstract}

Keywords: continuous casting; CAFE model; solidification structure; secondary cooling; superheat

\section{Introduction}

The solidification structure of continuous casting bloom (especially the center shrinkage and segregation of the bloom) has significant effects on the quality of the final products [1]. Center-equiaxed grains can effectively prevent the formation of solidification bridges and redistribute the residual impure liquid: The center segregation decreases as the center-equiaxed ratio increases. Furthermore, columnar grains will lead to the deterioration of mechanical properties [2]. For high-carbon big blooms, the solidification structure is difficult to evaluate and measure experimentally, because of the complicated branches and interactions and the huge number of grains. Therefore, numerical simulation has become an effective way to analyze the solidification behavior and structure during the continuous casting process. At present, deterministic [3], stochastic [4] and phase field approaches [5] are the main methods of modeling the solidification structure evolution of steels and alloys. Deterministic modeling cannot describe the probabilistic phenomena occurring in solidification and neglect the grain selection, equiaxed-columnar transition (CET) near to the mold wall. Phase field is suitable for the direct modeling of dendritic grain morphology, but needs huge computational resources and is limited to a relatively small equiaxed grain without a full side-branch structure. Stochastic methods include the Monte Carlo (MC) and cellular automaton (CA) techniques, although the former cannot be used to quantitatively investigate the effect of the various thermo-physical phenomena. The CA 
technique effectively describes the grain structure at a mesoscopic scale and the dendritic growth and arm branching at a microscopic scale. In the 1990s, Gandin et al. [6,7] developed the Cellular Automaton-Finite Element (CAFE) model by combining the CA technique with the finite element (FE) method. This CAFE model has been successfully applied in simulating the solidification behavior and structure [8-10]. In recent years, several published works have used the CAFE model to investigate the solidification structure during the continuous casting process [11-15]. However, most of them focus only on the structure during the continuous casting process and the heat transfer results associated with the solidification structure are ignored. It is known that both the heat transfer behavior and the temperature field are the foundations of the solidification structure, and the macroscopic heat transfer behavior and structure jointly decide the quality of the bloom.

The rapid development of high-speed railway in China is driving the gradual increase in demand of a higher quality of raw materials. In this paper, the solidification behavior, temperature field and solidification structure during the continuous casting process of $380 \mathrm{~mm} \times 280 \mathrm{~mm}$ heavy rail U71Mn bloom were numerically investigated using the CAFE model through ProCAST software. The thickness of the solidified shell, at two positions in the air-cooling zone under different secondary cooling conditions, was measured by nail shooting experiments to validate the model of macroscopic solidification. Macro etch experiments were also conducted to verify the model of solidification structure. Furthermore, the effects of both the secondary cooling types and superheat on the macroscopic solidification and structure are also discussed and compared to find ideal casting conditions for the bloom.

\section{Model Descriptions}

\subsection{Basic Assumptions}

To simplify the calculation process of the numerical simulation, the following four assumptions were made on the heat transfer characteristics and industrial conditions of the big bloom [16]:

(1) Heat transfer along the casting direction is ignored as it occurs much less in comparison to the heat transfer in the direction along the cross-sectional during the continuous casting process of round blooms.

(2) For the existence of interspace between the mold and bloom, the heat transfer in the mold can be calculated by the average heat flux.

(3) The effect of the fluid flow of molten steel on the internal heat transfer and structure is ignored during the calculations.

(4) Given that there is uniform heat transfer in each part of secondary cooling zone, the heat exchange of the bloom in the secondary cooling zone can be described by the heat transfer coefficient.

\subsection{Governing Equations}

\subsubsection{Thermal Transport}

The temperature field obeys the following unsteady heat flow equation [12]:

$$
\rho \cdot c_{\mathrm{p}} \frac{\partial T}{\partial t}=\frac{\partial}{\partial x}\left(\lambda \frac{\partial T}{\partial x}\right)+\frac{\partial}{\partial y}\left(\lambda \frac{\partial T}{\partial y}\right)
$$

where $T$ is the local temperature; $\lambda, \rho$ and $c_{\mathrm{p}}$ are the thermal conductivity, density and specific heat of the steel, respectively; $\frac{\partial T}{\partial x}$ and $\frac{\partial T}{\partial y}$ represent the temperature gradient at $x$ and $y$ direction. 


\subsubsection{Heterogeneous Nucleation}

The continuous nucleation model based on a Gaussian distribution is applied for heterogeneous nucleation [6,17]:

$$
\begin{gathered}
n(\Delta T)=\int_{0}^{\Delta T} \frac{\mathrm{d} n}{\mathrm{~d}(\Delta T)} \mathrm{d}(\Delta T) \\
\frac{\mathrm{d} n}{\mathrm{~d}(\Delta T)}=\frac{n_{\max }}{\sqrt{2 \pi} \Delta T_{\sigma}} \exp \left[-\frac{1}{2}\left(\frac{\Delta T-\Delta \bar{T}}{\Delta T_{\sigma}}\right)^{2}\right]
\end{gathered}
$$

where $n(\Delta T)$ is the number of nucleation sites for an undercooling temperature of $\Delta T ; \Delta \bar{T}$ is the mean nucleation undercooling; $\Delta T_{\sigma}$ is nucleation undercooling for the standard deviation; $n_{\max }$ is the maximum nucleation density.

\subsubsection{Kinetics of Dendritic Tip Growth}

The simplified KGT model (proposed by Kurz, Giovanola and Trivedi) [18] is applied to calculate the kinetics of dendritic tip growth. This is expressed in the following equation:

$$
v(\Delta T)=a_{2} \Delta T^{2}+a_{3} \Delta T^{3}
$$

where $a_{2}$ and $a_{3}$ are the fitting polynomial coefficients of the dendrite tip growth kinetic parameters; $v(\Delta \mathrm{T})$ is growth rate $(v)$ of dendrite tip when the undercooling temperature is $\Delta T$.

\section{Simulation Procedures and Model Validation}

\subsection{Model Building}

A $380 \mathrm{~mm} \times 280 \mathrm{~mm} \times 10 \mathrm{~mm}$ slice model with four $10 \mathrm{~mm}$ chamfered corners was developed in Pro/Engineer (5.0, Parametric Technology Corporation, Needham, MA, USA) then meshed with ProCAST software (2011.0, EIS Group, Paris, France). The total nodes and cells in the meshed model are 38,817 and 156,873, respectively. The meshed model is displayed in Figure 1.

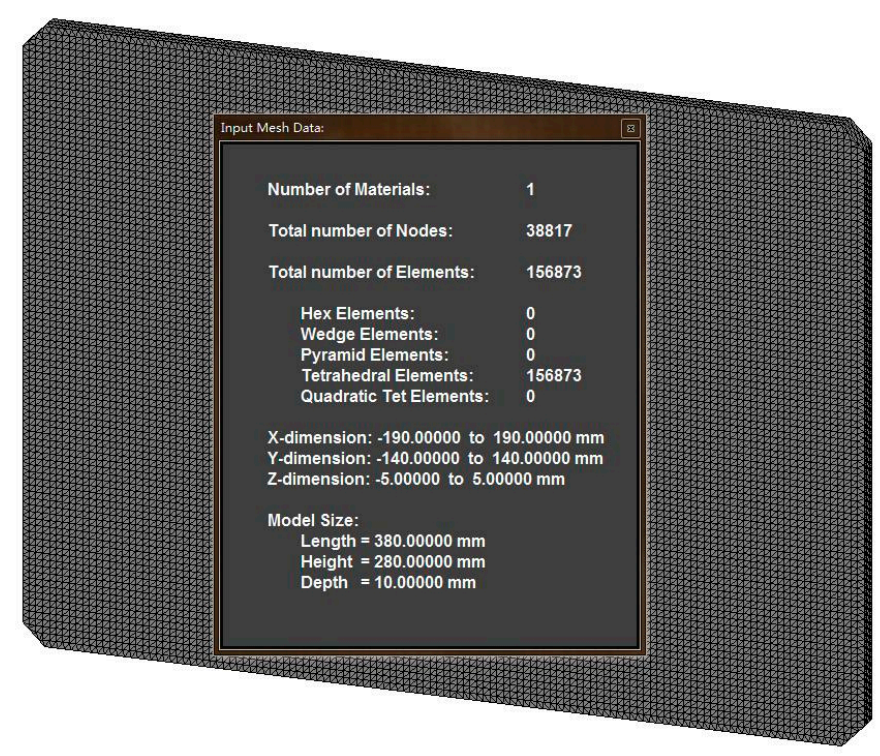

Figure 1. Exhibition of meshed slice model. 


\subsection{Casting Conditions and Parameters}

Table 1 lists the main parameters of the bloom-casting machine, where SSC and SC represent the super-slow cooling and the slow cooling conditions, respectively. Figure 2 shows the variation in the thermal-physical parameters (density, enthalpy, solid fraction and thermal conductivity) at various temperatures. These values are calculated through ProCAST by inputting the chemical compositions of the steel. Furthermore, the liquidus $\left(T_{1}\right)$ and solidus $\left(T_{\mathrm{S}}\right)$ temperature of the steel are 1746.15 and $1640.15 \mathrm{~K}$, respectively.

Table 1. Parameters of the bloom caster (SC: Slow cooling; SSC: Super-slow cooling).

\begin{tabular}{cc}
\hline Parameters & Value \\
\hline Arc radius, $\mathrm{m}$ & 12 \\
Bloom cross section, $\mathrm{mm}^{2}$ & $380 \times 280$ \\
Chamfer mold dimension, $\mathrm{mm}$ & 10 \\
Effective height of mold, $\mathrm{mm}$ & 700 \\
Secondary cooling system & Zone I: spray cooling \\
Maximum metallurgical length, $\mathrm{m}$ & Zone II V: air-mist cooling \\
Casting speed, $\mathrm{m} / \mathrm{min}$ & 26 \\
Water quantity in mold, $\mathrm{L} / \mathrm{min}$ & 0.63 \\
End of secondary cooling zone, $\mathrm{m}$ & 2600 \\
Secondary cooling water rate, $\mathrm{L} / \mathrm{kg}$ & 9.72 \\
\hline
\end{tabular}
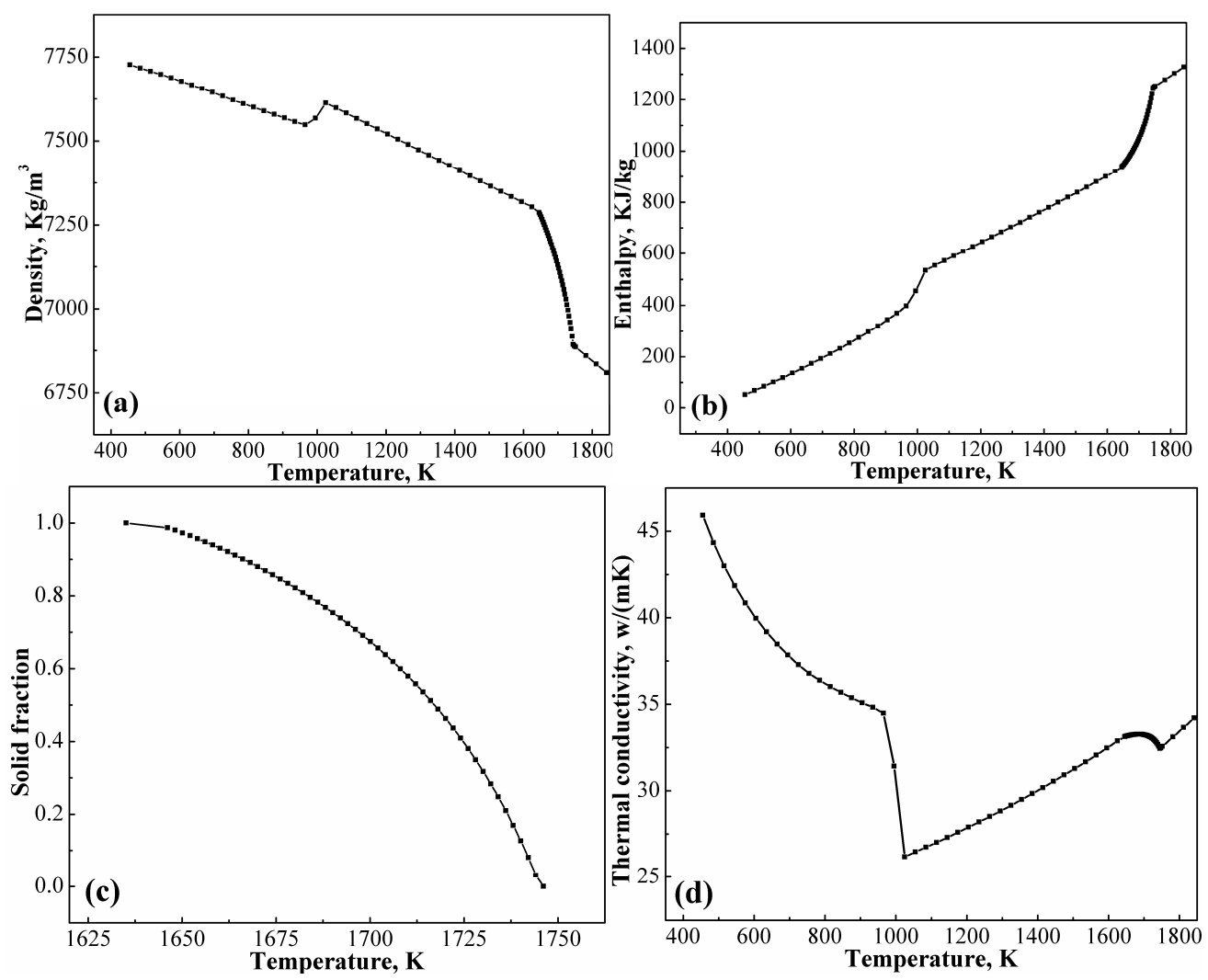

Figure 2. Variations of the thermo-physical parameters with temperature of U71Mn steel: (a) density; (b) enthalpy; (c) solid fraction; (d) thermal conductivity.

The high rail steel U71Mn is split into five main Fe-X binary systems: Fe-C, Fe-Si, Fe-Mn, Fe-P, and $\mathrm{Fe}-\mathrm{S}$. The composition $c_{0}$, liquidus slope $m$, partition coefficient $k$, and the solute diffusion coefficient 
$D$ of Fe- $X$ alloys and the Gibbs-Thompson coefficient $\Gamma$ are listed in Table 2. These values are also applied in the calculation of $a_{2}$ and $a_{3}$ [13]:

$$
\begin{gathered}
a_{2}=\left[\frac{-\rho}{2\left(m \cdot c_{0}\right)(1-k)^{2} \cdot k \cdot \Gamma}+\frac{1}{\left(m \cdot c_{0}\right)(1-k) \cdot D}\right] \frac{D^{2}}{\pi^{2} \Gamma} \\
a_{3}=\frac{D}{\pi \Gamma} \cdot \frac{1}{\left(m \cdot c_{0}\right)^{2}(1-k)}
\end{gathered}
$$

Table 2. Composition, liquidus slope, solute partition coefficient, diffusion coefficient, and GibbsThompson coefficient of binary Fe- $X$ steels.

\begin{tabular}{cccccc}
\hline Element & $\boldsymbol{c}_{\mathbf{0}}, \boldsymbol{\%}$ & $\boldsymbol{m}$ & $\boldsymbol{k}$ & $\boldsymbol{D}, \mathbf{~ m}^{\mathbf{2}} \mathbf{s}$ & $\boldsymbol{\Gamma}, \mathbf{m} \cdot \mathbf{K}$ \\
\hline $\mathrm{C}$ & 0.725 & -78 & 0.34 & $1.1 \times 10^{-8}$ & \\
$\mathrm{Si}$ & 0.355 & -21 & 0.05 & $3.5 \times 10^{-9}$ & \\
$\mathrm{Mn}$ & 0.985 & -5 & 0.68 & $2.4 \times 10^{-9}$ & $3 \times 10^{-7}$ \\
$\mathrm{P}$ & 0.014 & -34 & 0.06 & $4.7 \times 10^{-9}$ & \\
$\mathrm{~S}$ & 0.002 & -40 & 0.025 & $4.5 \times 10^{-9}$ & \\
\hline
\end{tabular}

Table 3 presents the nucleation parameter used in the CAFE model; the surface and internal nucleation undercooling $\left(\Delta T_{\mathrm{s}, \max }, \Delta T_{\mathrm{v}, \max }\right)$, standard deviation $\left(\Delta T_{\mathrm{s}, \sigma}, \Delta T_{\mathrm{v}, \sigma}\right)$ and initial nucleation density $\left(n_{\mathrm{s}}, n_{\mathrm{v}}\right)$ are listed. The value of $a_{2}$ and $a_{3}$ are calculated by the parameters in Table 2 .

Table 3. Nucleation parameters of CAFE (Cellular Automaton-Finite Element) model.

\begin{tabular}{ccccccccc}
\hline Parameters & $\boldsymbol{\Delta} \boldsymbol{T}_{\mathrm{s}, \max }, \mathrm{K}$ & $\boldsymbol{\Delta} \boldsymbol{T}_{\mathrm{s}, \boldsymbol{\sigma}}, \mathbf{K}$ & $\boldsymbol{n}_{\mathrm{s}}$ & $\boldsymbol{\Delta} \boldsymbol{T}_{\mathrm{v}, \max , \mathbf{K}}$ & $\boldsymbol{\Delta} \boldsymbol{T}_{\mathrm{v}, \boldsymbol{\sigma}}, \mathbf{K}$ & $\boldsymbol{n}_{\mathrm{v}}$ & $\boldsymbol{a}_{\mathbf{2}}$ & $\boldsymbol{a}_{\mathbf{3}}$ \\
\hline Value & 1 & 0.1 & $1 \times 10^{8}$ & 3.5 & 1 & $1 \times 10^{9}$ & $2.343 \times 10^{-6}$ & $2.7737 \times 10^{-6}$ \\
\hline
\end{tabular}

\subsection{Initial and Boundary Conditions}

The temperature of liquid steel in the slice is supposed to be equally distributed and equal with the temperature of liquid steel in tundish. The heat transfer boundary conditions for the bloom slice in each section of the caster can be set as follows. In the mold zone, the average heat flux is applied:

$$
\bar{q}=\frac{\rho_{\mathrm{w}} \cdot c_{\mathrm{W}} \cdot W \cdot \Delta T}{S}
$$

where $\rho_{\mathrm{W}}, c_{\mathrm{W}}, W$ and $\Delta T$ are the density, specific heat, flow rate, and temperature difference of cooling water, respectively; $S$ is the effective contact area.

In the secondary cooling zone, the heat transfer coefficient of the water spray condition is calculated from Equation (8), while Equation (9) is applied for air-mist cooling conditions:

$$
\begin{gathered}
h=\alpha \cdot\left[581 w^{0.541}\left(1-0.0075 T_{\mathrm{w}}\right)\right] \\
h=\beta \cdot(350 w+130)
\end{gathered}
$$

where $h$ and $w$ are the heat transfer coefficient and spray water density, respectively; $\alpha$ and $\beta$ are the correction factors.

In the air-cooling zone, the heat flux density can be calculated with the following equation:

$$
q=\varepsilon \cdot \sigma\left(T^{4}-T_{\mathrm{w}}^{4}\right)
$$

where $\sigma$ is the Steven-Boltzmann constant $\left(5.67 \times 10^{-8} \mathrm{~W} \cdot \mathrm{m}^{-2} \cdot \mathrm{K}^{-4)} ; \varepsilon\right.$ is the radiate heat transfer coefficient; $T$ and $T_{\mathrm{w}}$ are the temperatures of the bloom surface and the environment, respectively. 


\subsection{Model Validation}

\subsubsection{Validation of Heat Transfer}

A nail shooting experiment is one of the best ways to measure the thickness of the bloom solidified shell, being easy to operate and reliable. It is usually used to validate the simulation results of macroscopic solidification. During the continuous casting process, the nails with a tracer of sulfur are shot into the bloom perpendicular to the surface with a nail shooting gun. The nails have sufficient momentum to penetrate the solidified shell and the tips melt in the liquid. Thus, the sulfur is quickly distributed into the molten steel. After acid pickling and sulfur printing, the thickness of the solidified shell can be determined according to the morphology of sulfur. Detailed information about both the technique and the equipment used in the nail shooting experiment are reported elsewhere [19]. Two blooms under different secondary cooling conditions are tested. For each bloom, the shell thicknesses at two testing positions are measured. The testing positions at each bloom are $13 \mathrm{~m}(1 \#)$ and $14.83 \mathrm{~m}(2 \#)$ below the meniscus. Figure 3 shows part of the solidified sulfur printing samples from the nail shooting experiments: Black trace is the diffused sulfur in the nails. Figure 4 shows the contours of solid fraction distribution in the cross sections of testing points under the SSC (a) and SC (b) conditions, respectively. Table 4 compares measured and simulated solidified shell thickness.

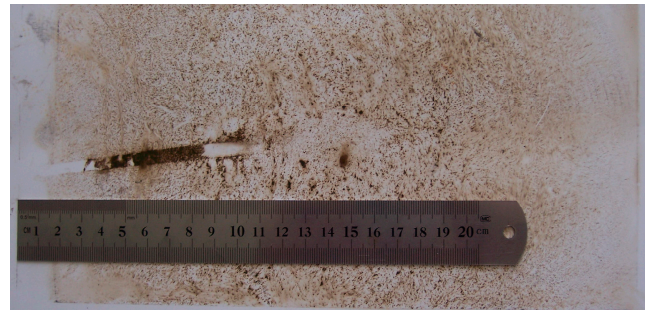

(a)

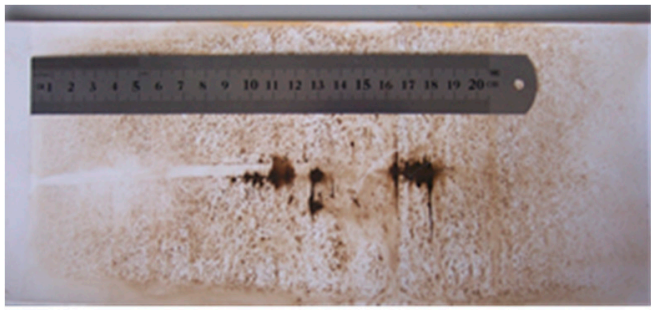

(b)

Figure 3. Photographs of sulfur printing samples for nail shooting experiments: (a) SSC (Super-slow cooling); (b) SC (Slow cooling).

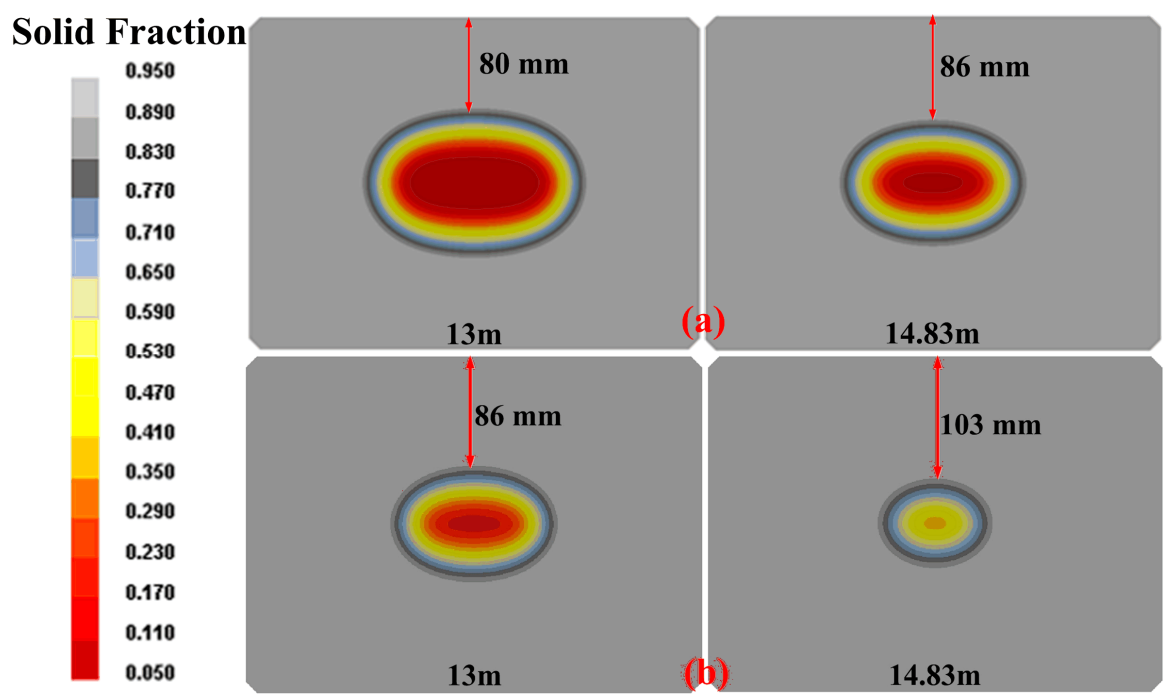

Figure 4. Solid fraction distributions at testing positions for SSC (a) and SC (b). 
Table 4. Comparison of measured and simulated solidified shell thickness.

\begin{tabular}{cccccc}
\hline Condition & Position, $\mathbf{m}$ & Measured, $\mathbf{m m}$ & Simulated, $\mathbf{m m}$ & Error, $\%$ & Liquid Core Length, $\mathbf{m}$ \\
\hline \multirow{2}{*}{ SCC } & 13.00 & 83 & 80 & 3.6 & \multirow{2}{*}{19.69} \\
& 14.83 & 88 & 86 & 2.3 & \multirow{2}{*}{ SC } \\
\multirow{2}{*}{ SC } & 13.00 & 89 & 86 & 3.4 & \multirow{2}{*}{. } \\
& 14.83 & - & 103 & - & \\
\hline
\end{tabular}

It can be seen from the experimental and numerical results that the thicknesses of the solidified shell at $13 \mathrm{~m}$ and $14.83 \mathrm{~m}$ below the meniscus are within $83-89 \mathrm{~mm}$ and $89-103 \mathrm{~mm}$ respectively (for a range of different cooling conditions), and solidification end is within 17.23-19.69 m. Compared to the measured results, the simulated solidified shell thickness errors are within $4 \%$. Thus, the heat transfer model is acceptable in this situation.

\subsubsection{Validation of Solidification Structure}

The industrial continuous casting blooms are polished and etched. The etching solution, $\mathrm{V}\left(\mathrm{HNO}_{3}\right): \mathrm{V}(\mathrm{HCI}): \mathrm{V}(\mathrm{HF}): \mathrm{V}\left(\mathrm{H}_{2} \mathrm{O}\right)=2.5: 1.5: 1: 95$, was used to etch the grain boundary, and the metallographic images were observed using a camera (Canon, Tokyo, Japan). Figure 5 shows the comparison of the numerical and experimental solidification structures under SSC (a) and SC (b), respectively, in which the superheat of each bloom is $25 \mathrm{~K}$. The percentages of center-equiaxed grains in the industrial blooms are about $27.9 \%$ for SSC and $28.2 \%$ for SC, while the calculated equiaxed grain ratios are $28.7 \%$ for SSC and $28.9 \%$ for SC.

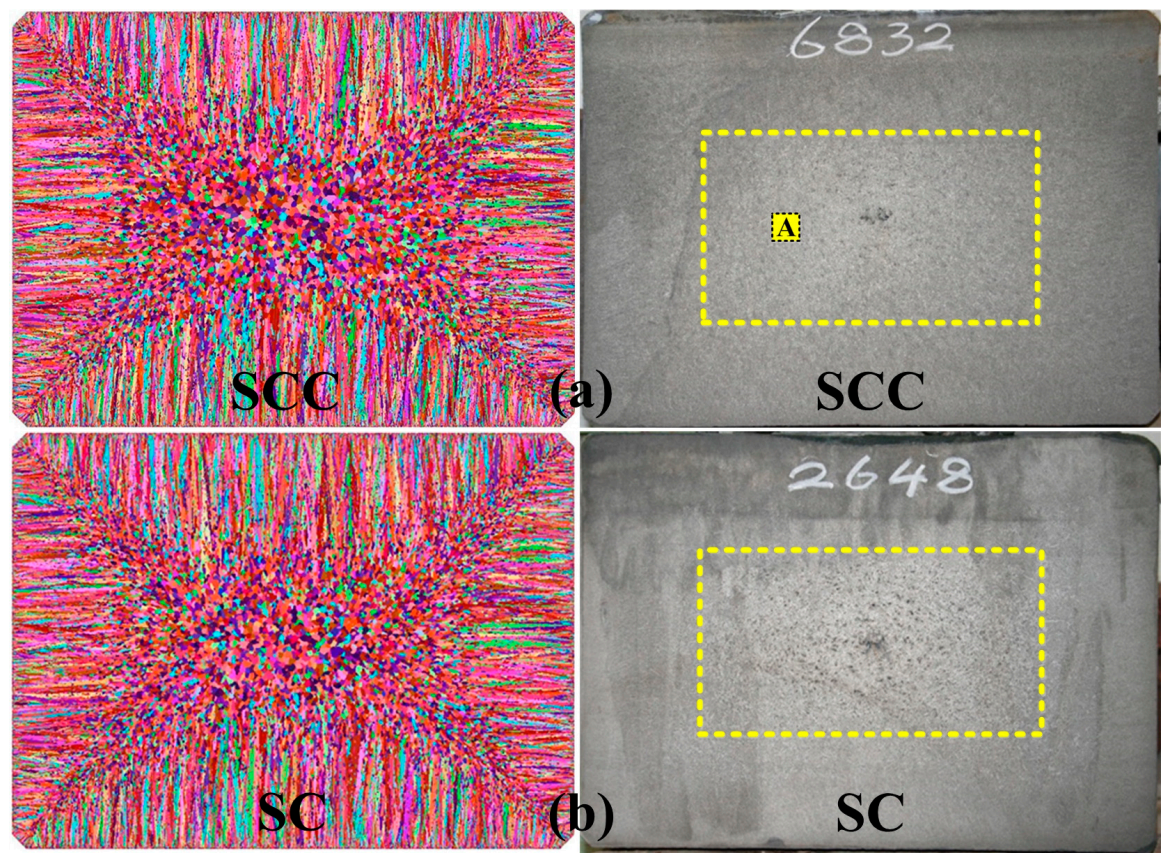

Figure 5. Comparison of numerical and experimental structure under SSC (a) and SC (b).

The solidification macrostructure at a quarter of the equiaxed grain zone (see position " $\mathrm{A}$ " on the right picture of Figure 5a) in the industrial bloom under SSC was observed by optical microscope $(\mathrm{OM})$. The solidification structures of this sample under ten fields of views were measured and one of the ten fields filmed by OM was showed in Figure 6. The averaged grain radius in the ten fields was counted to be around $0.678 \mathrm{~mm}$, and the statistical averaged grain radius of the simulated results at the same position is $0.689 \mathrm{~mm}$. 


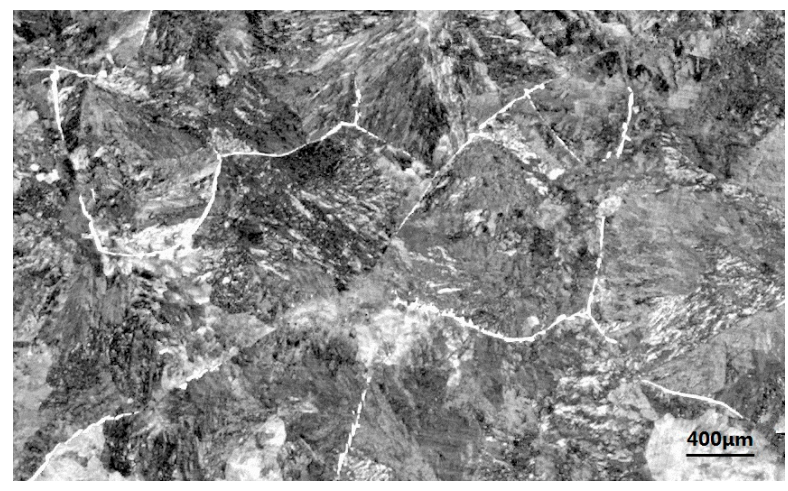

Figure 6. Micrographs showing macrostructure of center-equiaxed grains.

It can be seen that the simulation results of the solidification structure distributions and size are basically consistent with the experimental results.

\section{Results and Discussion}

\subsection{Effect of Secondary Cooling Types}

To investigate, more specifically, the effect of secondary cooling types on the temperature field, solidification process and structure in the continuous casting bloom, the numerical results of the heat transfer and structure under the two cases mentioned above are discussed and compared statistically in this part.

Figure 7 shows the temperature variations in the bloom center, wide surface and corner along the casting direction under different secondary cooling conditions. Figure 8 presents the contours of solid fraction distribution at the end of the secondary cooling zone $(z=9.72 \mathrm{~m})$ under different cooling conditions. Combining the information shown in Figures 4, 7 and 8, it can be seen that the secondary cooling condition has significant effects on the temperature field and solidification behavior of the continuous casting bloom. Compared to SC, the growth velocity of the solidifying shell is obviously smaller in SCC: The solidified shell thickness is $64 \mathrm{~mm}$ at $9.72 \mathrm{~m}$ below the meniscus, $80 \mathrm{~mm}$ at $13 \mathrm{~m}$ below the meniscus and $86 \mathrm{~mm}$ at $14.83 \mathrm{~m}$ below the meniscus for SCC; whereas the thicknesses of the solidified shell at the same positions are 76, 86 and $103 \mathrm{~mm}$, respectively, for SC. The metallurgical lengths under different secondary cooling conditions are $17.23 \mathrm{~m}$ for SC and $19.56 \mathrm{~m}$ for SSC, and the length of the mushy zone at the bloom center is $8.10 \mathrm{~m}$ for SC and $10.56 \mathrm{~m}$ for SSC. The surface and corner temperatures of the bloom under the SSC condition are relatively high. The surface temperature before the air-cooling zone is larger than $1370 \mathrm{~K}$ : Increasing from $1370 \mathrm{~K}$ at $9.72 \mathrm{~m}$ below the meniscus to $1410 \mathrm{~K}$ at $11.5 \mathrm{~m}$ below the meniscus when entering the air-cooling zone. It then decreases to $1270 \mathrm{~K}$ at $26 \mathrm{~m}$ below the meniscus. Whereas the surface temperature at the end of the secondary cooling zone under SC is $1255 \mathrm{~K}$. This increases to $1354 \mathrm{~K}$ at $12.5 \mathrm{~m}$ below the meniscus, where a remarkable rise happens in a short distance when entering the air-cooling zone, followed by a gradual decrease to $1227 \mathrm{~K}$ at $26 \mathrm{~m}$ below the meniscus. The temperature variations of the bloom corner under different secondary cooling conditions have a similar changing trend as the surface temperature. The corner temperatures under different secondary cooling conditions are $1070 \mathrm{~K}$ for SSC and $930 \mathrm{~K}$ for SC at end of secondary cooling zone, followed by an increase to $1200 \mathrm{~K}$ at $13.92 \mathrm{~m}$ below the meniscus for SCC and $1140 \mathrm{~K}$ at $17.34 \mathrm{~m}$ below the meniscus for SC. A rise of more than $150 \mathrm{~K}$ happens within the first two meters of the air-cooling zone for the SC condition. Higher surface and corner temperatures, as well as smaller temperature rise per meter, result in less opportunity to cause bloom surface cracks. 


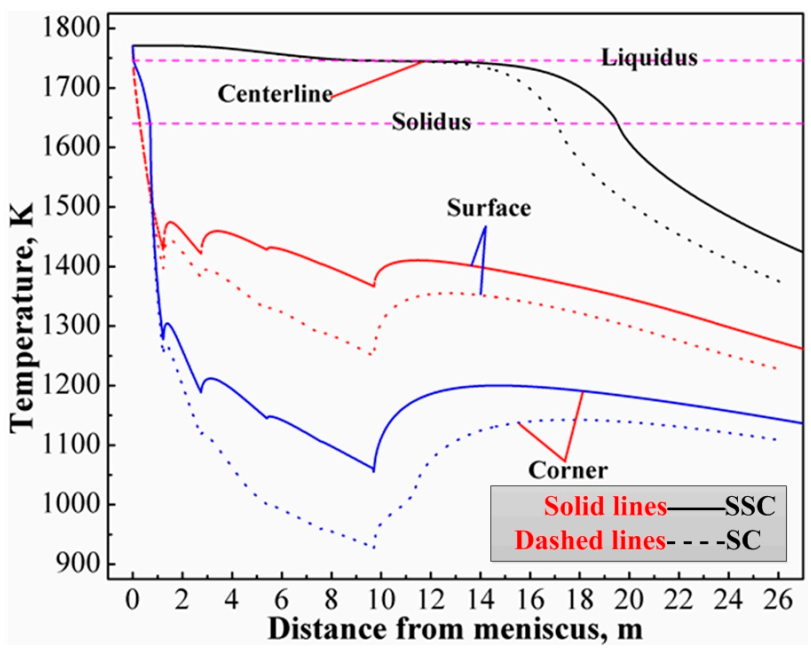

Figure 7. Center, surface and corner temperature variations along casting direction for SSC and SC.

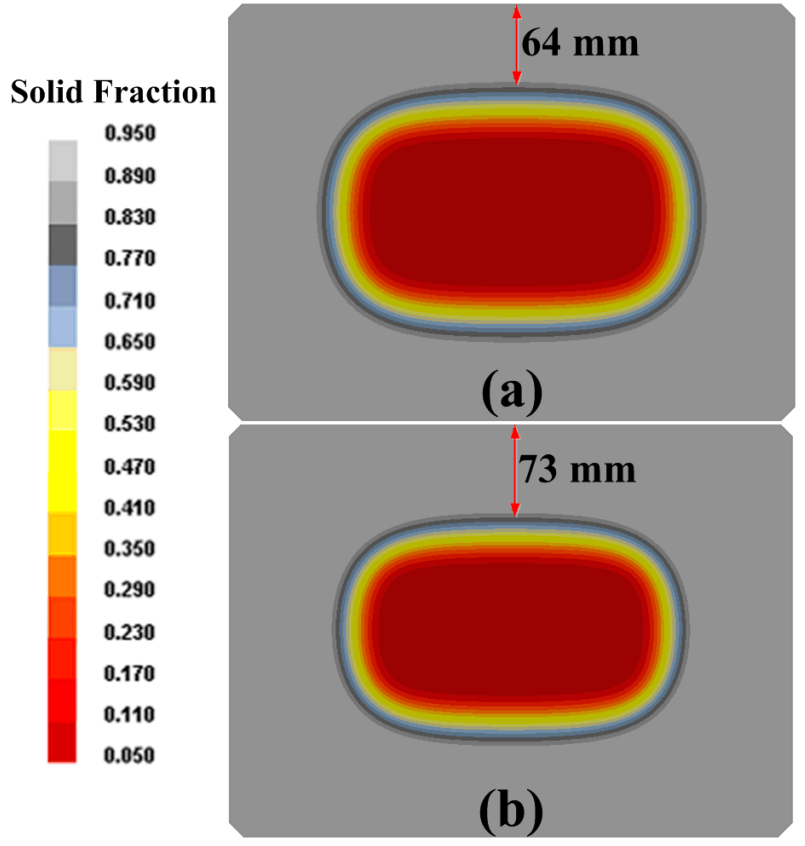

Figure 8. Contours of solid fraction at end of secondary cooling zone under SSC (a) and SC (b).

The numerical results of the solidification structure of the bloom under SCC (a) and SC (b) are presented in Figure 5. As it is not possible to visually detect the grain difference between these two cases, a statistical analysis is particularly necessary in this situation. Table 5 provides a comparison of the statistic grain parameters under different secondary cooling conditions in a quarter of bloom cross section. No. Grains and Mean Surf represent the total number of the grains and average surface area of each grain, respectively; Equiaxed ratio is the ratio of equiaxed grain in the bloom center; $\mathrm{Nl}$ and $\mathrm{Na}$ are the grain number per meter and per square meter, respectively. It can be seen that the total grain number, $\mathrm{Nl}, \mathrm{Na}$ and the center-equiaxed grain ratio under $\mathrm{SC}$ are slightly larger when compared with the SSC condition, while the grain mean surface area and mean radius are a little smaller. The grain average radius is about $1.089 \mathrm{~mm}$ for SSC and $1.066 \mathrm{~mm}$ for SC, and the ratios of bloom center-equiaxed grain are around $28.7 \%$ for SSC and $28.9 \%$ for SC. Comparing the parameters of the grain sizes and distributions under SSC and SC, it is evident that the secondary cooling condition 
has limited effects on the solidification structure of the bloom, because both the SSC and SC themselves belong to the slow cooling conditions.

Table 5. Statistic grain parameters under different cooling conditions ( $1 / 4$ cross section).

\begin{tabular}{ccccccc}
\hline Condition & No. Grains & Mean Surf/m ${ }^{2}$ & $\mathbf{N 1} / \mathbf{m}$ & $\mathbf{N a} / \mathbf{m}^{2}$ & Mean Radius/m & Equiaxed Ratio $\%$ \\
\hline SSC & 16,357 & $1.623196 \times 10^{-6}$ & $1.053651 \times 10^{3}$ & $6.160937 \times 10^{5}$ & $1.088757 \times 10^{-3}$ & 28.7 \\
SC & 17,303 & $1.534888 \times 10^{-6}$ & $1.091288 \times 10^{3}$ & $6.517252 \times 10^{5}$ & $1.065995 \times 10^{-3}$ & 28.9 \\
\hline
\end{tabular}

After comprehensively considering the results of the temperature field and solidification structure under SCC and SC, in order to reduce the chance of bloom surface defects, center porosity and segregation, the super-slow cooling condition is more acceptable for continuous casting blooms.

\subsection{Effect of Superheat}

Qu et al. [20] numerically analyzed the solidification structure of a $280 \mathrm{~mm} \times 325 \mathrm{~mm}$ continuous casting bloom and discussed the effect of casting speed and superheat on the solidification structure. They found that the final solidification structure changed less when the casting speed fluctuation was within $\pm 0.5 \mathrm{~m} / \mathrm{min}$ and that the casting temperature had significant effects on the structure. They also found that the grain size increased as the superheat was enhanced, and the ratio of center-equiaxed grain decreased as the superheat increased. To guarantee bloom quality, finding an appropriate casting superheat for bloom casting is essential.

Figure 9 presents the temperature variations of the bloom surface and centerline along the casting direction under different superheat. In this study, the superheat values that were considered are 15, 20, 25, 30 and $40 \mathrm{~K}$, and the secondary cooling condition used in these cases was SSC. It can be seen from Figure 9 that the superheat has little effect on the solidification length and surface temperature of the bloom during the continuous casting process. The bloom solidifies end elongates from 19.15 to $20.10 \mathrm{~m}$ as the superheat increases from 15 to $40 \mathrm{~K}$ : each $5 \mathrm{~K}$ rise in the superheat results in a metallurgical length increase of about $0.19 \mathrm{~m}$ and about a $3 \mathrm{~K}$ rise in bloom surface temperature.

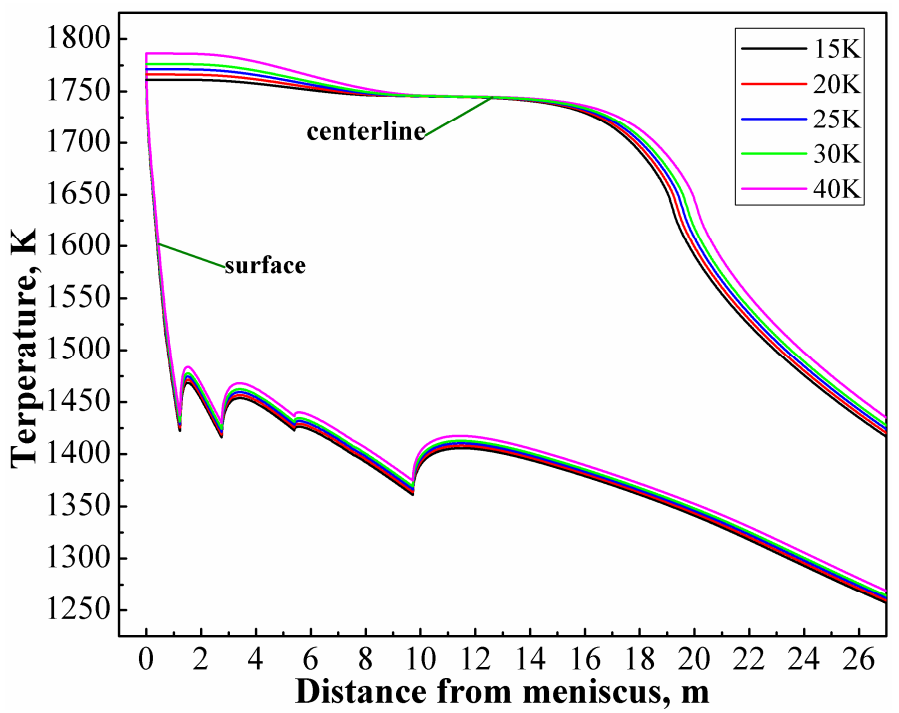

Figure 9. Temperature variations of bloom surface and centerline along the casting direction under different superheat.

Figure 10 presents the simulated solidification structure in the bloom under different superheat. Table 6 lists the statistics results of the grain parameters and distributions in a quarter of the bloom cross-section under different superheat. It can be clearly seen that the ratio of center-equiaxed grain 
markedly deceases as superheat increases. Increasing superheat also causes the columnar grains to grow bigger and the coarse columnar crystal sites to become larger. The total number of grains is 17,666 when superheat is $15 \mathrm{~K}$, decreasing to 14,771 when the superheat rises to $40 \mathrm{~K}$. The average surface area of the grains increases from $1.503 \times 10^{-6} \mathrm{~m}^{2}$ when the superheat is $15 \mathrm{~K}$ to $1.797 \times 10^{-6} \mathrm{~m}^{2}$ when the superheat is $40 \mathrm{~K}$. The average radius of grain increases from 1.025 to $1.128 \mathrm{~mm}$ at the same time. The grain number per meter and per square meter decreases as the superheat increases, and the ratio of center-equiaxed grains markedly changes. The percentages of center-equiaxed grain under different superheat are $44.6 \%$ for $15 \mathrm{~K}, 33.8 \%$ for $20 \mathrm{~K}, 28.7 \%$ for $25 \mathrm{~K}, 24.5 \%$ for $30 \mathrm{~K}$ and $20.1 \%$ for $40 \mathrm{~K}$. The difference in the grain parameters and distributions between $15 \mathrm{~K}$ and $20 \mathrm{~K}$ is very small: the average radius only increases by about $0.011 \mathrm{~mm}$. The difference in grain size between $20 \mathrm{~K}$ and $25 \mathrm{~K}$ is relatively bigger. In particular, the average radius increases by about $0.052 \mathrm{~mm}$. The size of both columnar and equiaxed grains remains at a relative low level, and the ratio of center-equiaxed crystal is high, when the superheat is within $20 \mathrm{~K}$. Whereas the percentage of equiaxed grains decreases, the columnar crystal grows larger, and the average grain size increase suddenly when the superheat is over $20 \mathrm{~K}$. For big-bloom castings, the quality of final products will be improved if the superheat is properly decreased when the casting temperature meets the required level for a normal production process. The casting temperature should not be either too low or too high: low superheat can easily cause nozzle clogging during the pouring process and high superheat will lead to a low percentage of center-equiaxed grain, serious center porosity and macrosegregation. Usually, the casting superheat for high-carbon steel is controlled within 25-30 K in many steelmaking plants. However, it can be reduced to within $20 \mathrm{~K}$ with the application of either tundish heating or insulation technologies during the pouring process. In this case, the percentage of center-equiaxed grain can be controlled by more than $33.8 \%$, and average grain radius is smaller than $1.04 \mathrm{~mm}$ when the casting superheat is within $20 \mathrm{~K}$.

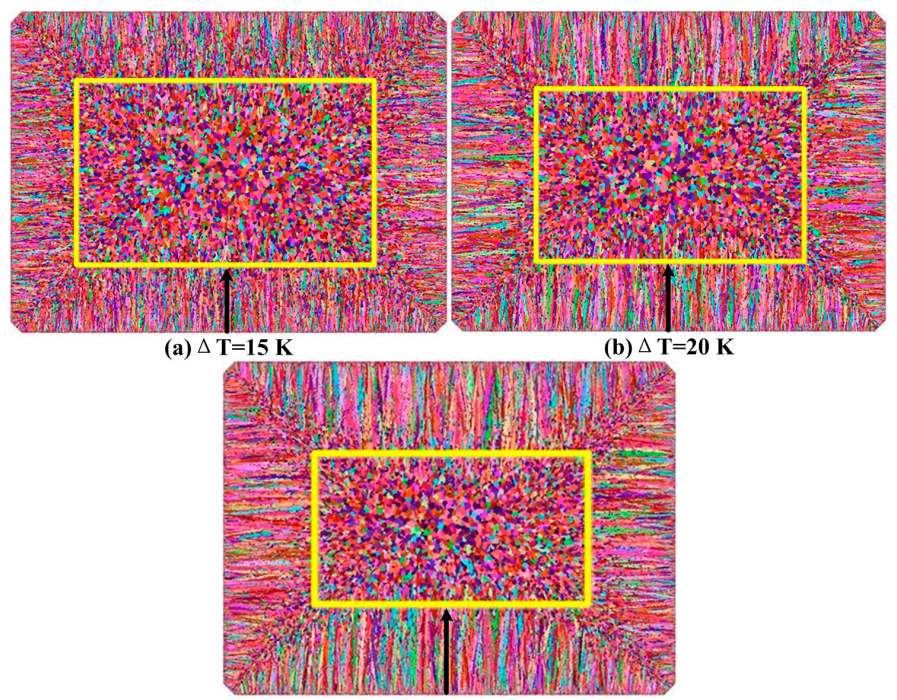

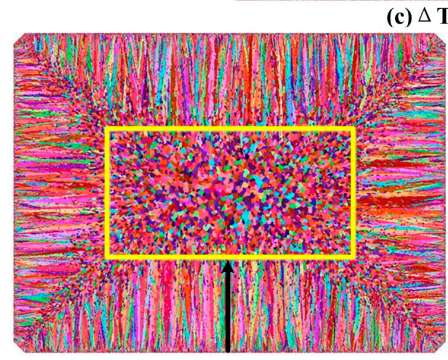

(d) $\Delta \mathrm{T}=30 \mathrm{~K}$

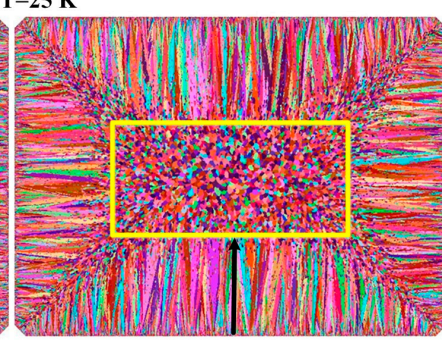

(e) $\Delta \mathrm{T}=40 \mathrm{~K}$

Figure 10. Solidification structure in the bloom under different superheat: (a) $15 \mathrm{~K}$, (b) $20 \mathrm{~K}$, (c) $25 \mathrm{~K}$, (d) $30 \mathrm{~K}$, (e) $40 \mathrm{~K}$. 
Table 6. Statistic of grain parameters in the bloom under different superheat ( $1 / 4$ section).

\begin{tabular}{ccccccc}
\hline$\Delta \boldsymbol{T}$ & No. Grains & Mean Surf/ $\mathbf{m}^{\mathbf{2}}$ & $\mathbf{N l} / \mathbf{m}$ & $\mathbf{N a} / \mathbf{m}^{2}$ & Mean Radius/m & Equiaxed Ratio $\%$ \\
\hline 15 & 17,666 & $1.502860 \times 10^{-6}$ & $1.071519 \times 10^{3}$ & $6.653978 \times 10^{5}$ & $1.025176 \times 10^{-3}$ & 44.6 \\
20 & 17,315 & $1.533325 \times 10^{-6}$ & $1.061892 \times 10^{3}$ & $6.521773 \times 10^{5}$ & $1.036561 \times 10^{-3}$ & 33.8 \\
25 & 16,357 & $1.623195 \times 10^{-6}$ & $1.053651 \times 10^{3}$ & $6.160938 \times 10^{5}$ & $1.088757 \times 10^{-3}$ & 28.7 \\
30 & 15,830 & $1.681266 \times 10^{-6}$ & $1.030924 \times 10^{3}$ & $5.961813 \times 10^{5}$ & $1.101718 \times 10^{-3}$ & 24.5 \\
40 & 14,771 & $1.797409 \times 10^{-6}$ & $9.854707 \times 10^{2}$ & $5.563564 \times 10^{5}$ & $1.127640 \times 10^{-3}$ & 20.1 \\
\hline
\end{tabular}

\section{Conclusions}

The solidification behavior and structure of the continuous casting process under different secondary cooling conditions and superheat were discussed and compared in this paper, and both nail-shooting and macro etch experiments were conducted to validate the numerical results of solidification behavior and structure, respectively. The conclusions are summarized as follows:

(1) The simulated results of the solidified shell, solidification structure distributions and equiaxed grain size are basically consistent with the nail shooting, macro etch experiments and OM observations; errors in the shell thickness are controlled within $4 \%$.

(2) Compared to the slow cooling condition, the solidification end of the bloom is $2.46 \mathrm{~m}$ longer and the length of the bloom center mushy zone increases by about $1.46 \mathrm{~m}$ under the super-slow cooling condition. However, the bloom surface and corner temperatures are higher, and the degree of temperature rise when entering air-cooling zone is much smaller. Furthermore, the solidification structure shows little change under these two secondary cooling conditions.

(3) As the superheat increases, the average grain size increases, while there is an apparent decrease in the percentage of center-equiaxed grains. When the superheat increases from 15 to $40 \mathrm{~K}$, the center-equiaxed grain ratio decreases from $44.6 \%$ to $20.1 \%$ and the grain average radius increases from 1.025 to $1.128 \mathrm{~mm}$. The difference in grain size between 15 and $20 \mathrm{~K}$ is tiny. A step size increase in the superheat of $5 \mathrm{~K}$ causes an increase of only about $0.19 \mathrm{~m}$ in the solidification end length, and an increase of $3 \mathrm{~K}$ in the surface temperature. The super heat should be controlled within $20 \mathrm{~K}$.

Acknowledgments: The authors would like to express their gratitude for the financial support by the National Natural Science Foundation of China No. 51471122, 51604200 and 51774217, and the Key Program of Natural Science Foundation of Hubei Province of China No. 2015CFA128.

Author Contributions: Hongwei Ni and Hua Zhang conceived and designed the study. Qing Fang performed the experiments and simulations. Bao Wang and Chengsong Liu contributed to the result analysis and paper preparation. Qing Fang wrote the manuscript.

Conflicts of Interest: The authors declare no conflict of interest.

\section{References}

1. Yamazaki, M.; Natsume, Y.; Harada, H.; Ohsasa, K. Numerical simulation of solidification structure formation during continuous casting in Fe-0.7 Mass\% C alloy using cellular automaton method. ISIJ Int. 2006, 46, 903-908. [CrossRef]

2. Straffelini, G.; Lutterotti, L.; Tonolli, M.; Lestani, M. Modeling solidification structures of steel round billets obtained by continuous casting. ISIJ Int. 2011, 51, 1448-1453. [CrossRef]

3. Anand, G.; Datta, S.; Chattopadhyay, P.P. Deterministic approach for microstructurally engineered formable steel. Int. J. Metall. Eng. 2013, 2, 69-78.

4. Nastac, L. A 3D stochastic mesoscopic model for prediction of, structure evolution during solidification of dendritic alloys. Metall. Res. Technol. 2014, 111, 311-319. [CrossRef]

5. Rezende, J.; Senk, D.; Hüttenmeister, D. Phase-field modeling of the dendrite growth morphology with influence of solid-liquid interface effects. Steel Res. Int. 2015, 86, 65-72. [CrossRef]

6. Rappaz, M.; Gandin, C.A. Probabilistic modelling of structure formation in solidification processes. Acta Mater. 1993, 41, 345-360. [CrossRef] 
7. Gandin, C.A.; Desbiolles, J.L.; Rappaz, M.; Thevoz, P. A three-dimensional cellular automation-finite element model for the prediction of solidification grain structures. Metall. Mater. Trans. A 1999, 30, 3153-3165. [CrossRef]

8. Zhu, H.; Jiang, Z.; Li, H.; Zhu, J.; Feng, H.; Zhang, S.; Zhang, B.; Wang, P.; Liu, G. Effect of solidification pressure on compactness degree of $19 \mathrm{Cr} 14 \mathrm{Mn} 0.9 \mathrm{~N}$ high nitrogen steel using CAFE method. Steel Res. Int. 2017, 88, 1600509, in press. [CrossRef]

9. Zhang, H.; Zhang, L. Modeling on the solidification structure of Fe-Ni-based alloys using cellular automaton method. Metall. Res. Technol. 2016, 113, 410. [CrossRef]

10. Song, W.; Zhang, J.; Wang, S.; Wang, B.; Han, L. Simulation of solidification structure of Fe-6.5\% Si alloy using cellular automaton-finite element method. J. Cent. South Univ. 2016, 23, 2156-2164. [CrossRef]

11. Luo, Y.Z.; Zhang, J.M.; Wei, X.D.; Xiao, C.; Hu, Z.F.; Yuan, Y.Y.; Chen, S.D. Numerical simulation of solidification structure of high carbon SWRH77B billet based on the CAFE method. Ironmak. Steelmak. 2013, 39, 26-30. [CrossRef]

12. Zeng, J.; Chen, W. Effect of secondary cooling conditions on solidification structure and central macrosegregation in continuously cast high-carbon rectangular billet. High Temp. Mater. Process. 2015, 34, 577-583. [CrossRef]

13. Bai, L.; Wang, B.; Zhong, H.; Ni, J.; Zhai, Q.; Zhang, J. Experimental and numerical simulations of the solidification process in continuous casting of slab. Metals 2016, 6, 53. [CrossRef]

14. Hou, Z.; Cheng, G.; Jiang, F.; Qian, G. Compactness degree of longitudinal section of outer columnar grain zone in continuous casting billet using cellular automaton-finite element method. ISIJ Int. 2013, 53, 655-664. [CrossRef]

15. Fang, Q.; Ni, H.W.; Wang, S.J.; Zang, H. Numerical simulation on the solidification structure of $\varnothing 600 \mathrm{~mm}$ continuous casting round bloom. IOP Conf. Ser. Mater. Sci. Eng. 2016, 117, 012036. [CrossRef]

16. Lally, B.; Biegler, L.; Henein, H. Finite difference heat transfer modeling for continuous casting. Metall. Mater. Trans. B 1990, 21, 761-770. [CrossRef]

17. Gandin, C.A.; Rappaz, M. A coupled finite element-cellular automaton model for the prediction of dendritic grain structures in solidification processes. Acta Metall. Mater. 1994, 42, 2233-2246. [CrossRef]

18. Kurz, W.; Giovanola, B.; Trivedi, R. Theory of microstructural development during rapid solidification. Acta Mater. 1986, 34, 823-830. [CrossRef]

19. Long, M.J.; Chen, D.F.; Wang, Q.X.; Luo, D.H.; Han, Z.W.; Liu, Q.; Gao, W.X. Determination of CC slab solidification using nail shooting technique. Ironmak. Steelmak. 2012, 39, 370-377. [CrossRef]

20. Qu, T.; Wang, S.; Feng, K. Numerical simulation on solidification structure of bloom during continuously casting process. Contin. Cast. 2013, 1, 7-11. (In Chinese) 